\title{
TLE3 is not a predictive biomarker for taxane sensitivity in the NCIC CTG MA.21 clinical trial
}

\author{
J M S Bartlett ${ }^{\star}, 1, \mathrm{~T}$ O Nielsen ${ }^{2}, \mathrm{D} \mathrm{Gao}{ }^{2}, \mathrm{~K} \mathrm{~A} \mathrm{Gelmon}{ }^{3}, \mathrm{M} \mathrm{A}$ Quintayo ${ }^{1}$, J Starczynski ${ }^{1}, \mathrm{~L} \mathrm{Han}^{4}$, M J Burnell ${ }^{5}$, \\ M N Levine ${ }^{6}$, B E Chen ${ }^{4}$, L E Shepherd ${ }^{4}$ and J W Chapman ${ }^{4}$ on behalf of the NCIC CTG ${ }^{4}$ \\ ${ }^{1}$ Ontario Institute for Cancer Research, 661 University Avenue, Suite 510, Toronto, Ontario M5G 0A3, Canada; ${ }^{2}$ Genetic Pathology \\ Evaluation Centre, British Columbia (BC) Cancer Agency, Vancouver, British Columbia V5Z 1M9, Canada; ${ }^{3}$ BC Cancer Agency, \\ University of British Columbia, Vancouver, British Columbia V5Z 4E6, Canada; ${ }^{4} \mathrm{NCIC}$ Clinical Trials Group, Queen's University, 10 \\ Stuart Street, Kingston, Ontario K7L 3N6, Canada; ${ }^{5}$ Saint John Regional Hospital, Saint John, New Brunswick E2L 4L4, Canada and \\ ${ }^{6}$ Juravinski Cancer Clinic, Hamilton Health Sciences, McMaster University, Hamilton, Ontario L8V 5C2, Canada
}

Background: TLE3, a nuclear transcriptional repressor downstream of WNT signalling pathways, has been hypothesised as predictive of benefit from adjuvant taxane.

Methods: MA.21 tissue microarrays were constructed from 1097 out of 2104 (52\%) patients. TLE3 staining by immunohistochemistry used validated methodology. Continuous TLE3 + (percentage of cells staining positive) was assessed with both visual and automated scoring. The primary objective was to test the predictive effect of TLE3 on relapse-free survival using the MA.21 $E C / T$ and $C E F$ arms and the previously defined cut-point of $30 \%$ of cells staining positive in $\geqslant 1$ core/tumour.

Results: MA.21 patients had 83.2\% TLE3 positive (TLE3+) tumours by visual score and $80.6 \%$ TLE3 + by automated image analysis while the previously observed rate of TLE3 + cases was $58.6 \%$. TLE3 expression was significantly associated with ER expression (91.2\% of ER-positive tumours were TLE3 $+; P<0.0001$ ). At median 8-year follow-up, there was no evidence of a predictive effect of TLE3 expression with respect to taxane benefit using the established $30 \%$ or exploratory quartile cut-points.

Conclusions: Proportionately more MA.21 patient tumours than expected were TLE3 + . The pre-specified TLE3 + cut-point of $30 \%$ was not predictive of taxane benefit. TLE3 expression does not represent a viable biomarker for taxane benefit in breast cancer.

For decades, adjuvant chemotherapy has been administered without reference to underlying tumour biology. TLE3, a nuclear transcriptional repressor, has emerged as a strong candidate marker of response to chemotherapeutics with cell cycle stagespecific activity. The TLE family of proteins act as transcriptional repressors downstream of APC and $\beta$-catenin in the WNT (Wingless Type) pathway (Liu et al, 1996; Leon and Lobe, 1997; Allen et al, 2006). Disruption of this pathway modifies the cellular cytoskeleton, an established target of taxanes (Kulkarni et al, 2009); therefore, it is plausible that TLE3 expression reflects integrity of this pathway and taxane sensitivity. Taxanes (paclitaxel and docetaxel) are used to treat breast cancer with variable success (Peto et al, 2012). The diversity of molecular sub-types of breast cancer is one likely explanation for this variability, and recent studies have explored the use of biomarkers including AKT1, tau, topoisomerase, ER/PR and HER-2 in an attempt to identify those patients most likely to respond to taxanes (Hayes et al, 2007; Pusztai, 2007; Lai et al, 2011; Bartlett et al, 2013). Identification of high quality, novel biomarkers that can be easily adopted for clinical use will enable clinicians to target treatment to those who will gain the most benefit from therapy.

TLE1 has been confirmed as a diagnostic biomarker for synovial sarcomas driving oncogenesis (Shon et al, 2011; Su et al, 2012). TLE1 and TLE3 splice isoforms have also been identified in prostate carcinoma and, when overexpressed in mice, promote lung adenocarcinoma (Nakaya et al, 2007; Metzger et al, 2012). 
Evidence that TLE3 acts as a taxane biomarker was derived from data mining on a 'discovery cohort' (Kulkarni et al, 2009) in which TLE3 was associated in the adjuvant setting with a lower risk of recurrence in patients treated with cytotoxic chemotherapy. This association was present only when patients were treated with a taxane-containing regimen. This association between TLE3 staining and outcome among women treated with taxanes was subsequently validated in independent cohorts of triple negative breast cancer patients (Kulkarni et al, 2009; Basu et al, 2012) and in separate studies of ovarian cancers (Samimi et al, 2012) and was linked to chemotherapy response in non-small cell lung cancer (Ross et al, 2010). These clinical results support the hypothesis that TLE3 is associated with response to taxane treatment. However, data in wider trails of breast cancer, including luminal and HER2positive cancers, are lacking. We performed the first prospectively planned validation of TLE3 as a biomarker of taxane benefit to test the predictive value of TLE3 for taxane benefit in the context of a phase III clinical trial.

We performed prospectively designed analyses to test the hypothesis that TLE3 expression acts as a predictive biomarker for benefit from taxanes in the NCIC Clinical Trial Group (CTG) MA.21 clinical trial. If successful, this analysis would provide level 2 evidence for the utility of TLE3 as a predictive biomarker of taxane benefit (Simon et al, 2009). MA.21 patients were randomised to two taxane-containing polychemotherapy regimens (epirubicin, fluorouracil, and paclitaxel (EC/T) and doxorubicin, adriamycin, and cyclophosphamide $(\mathrm{AC} / \mathrm{T})$ ) and to cyclophosphamide, epirubicin, and fluorouracil (CEF) (Burnell et al, 2012). Patients on the three arms experienced significantly different relapse-free survival $(\mathrm{RFS} ; P$-value $=0.001) . \mathrm{EC} / \mathrm{T}$ and $\mathrm{CEF}$ had similar RFS $(P=0.69)$, while AC/T was inferior to both CEF (hazard ratio (HR) $1.45,95 \%$ confidence interval (CI) $1.16-1.80 ; P=0.001)$ and to EC/T (HR 1.49 95\% CI 1.19-1.86; $P=0.0004)$.

\section{MATERIALS AND METHODS}

The NCIC CTG MA.21 trial (Registration ID: NCT00014222) was an international phase III trial (Burnell et al, 2010; Burnell et al, 2012). The study protocol was approved by the institutional ethics review board of each participating centre, and informed consent was obtained before assignment to treatment. Patients were randomised to: CEF (cyclophosphamide $75 \mathrm{mg} \mathrm{m}^{-2}$ orally, days 1-14; epirubicin $60 \mathrm{mg} \mathrm{m}^{-2} \mathrm{IV}$, days 1 and 8 and fluorouracil $500 \mathrm{mg} \mathrm{m}^{-2} \mathrm{IV}$, days 1 and 8; cotrimoxazole two tablets orally bid or ciprofloxacin $500 \mathrm{mg}$ orally bid during chemotherapy; filgrastim and epoetin permitted) for six 28-day cycles; EC/T (EC (epirubicin $120 \mathrm{mg} \mathrm{m}^{-2}$ and cyclophosphamide $830 \mathrm{mg} \mathrm{m}^{-2}$, both IV day 1) for six 14-day cycles; followed by T (paclitaxel $175 \mathrm{mg} \mathrm{m}^{-2} \mathrm{IV}$ day 1) every 21 days for four cycles; filgrastim $5 \mu \mathrm{g} \mathrm{kg}^{-1}$ subcutaneously, days 2-13; epoetin $40000 \mathrm{U}$ subcutaneously weekly); and $\mathrm{AC} / \mathrm{T}$ (AC (doxorubicin $60 \mathrm{mg} \mathrm{m}^{-2}$ and cyclophosphamide $600 \mathrm{mg} \mathrm{m}^{-2}$ both IV day 1) for four 21-day cycles; followed by $\mathrm{T}$ (paclitaxel $175 \mathrm{mg} \mathrm{m}^{-2}$ IV) every 21 days for four cycles; filgrastim and epoetin permitted). Stratification was by number of positive nodes $(0,1-3,4-10$, and $>10)$, type of surgery (total vs partial mastectomy), and ER status (ER positive $v s$ ER negative).

Patient population and tissue banking. Women were eligible for MA.21 if aged 60 or younger, with axillary node-positive or high risk node-negative breast cancer, and had undergone complete resection of all known disease including axillary node clearance. Baseline trial patient and tumour characteristics considered in this investigation were age, race, ECOG performance status, type of surgery, number of involved lymph nodes, pathologic $\mathrm{T}$ and $\mathrm{N}$ stage, ER and menopausal status, Her2/neu status, and adjuvant administration of radiotherapy, endocrine therapy, and Herceptin.

Tissue blocks were collected for 1097 (52\%) of the 2104 MA.21 patients; all of these patients gave informed consent for tissue to be used for research. Tissue microarrays (TMAs) were constructed from up to $4 \times 0.6 \mathrm{~mm}$ diameter cores from tissue block(s) for each patient, and arrayed in accordance with existing guidelines (Leyland-Jones et al, 2008; Rimm et al, 2011).

Study end point. The MA.21 primary end point was RFS defined as the time from randomisation to the date of first confirmed relapse; censoring was at longest follow-up or death without relapse. This end point was used for these investigations.

Primary objective. The primary aim was to examine the RFS predictive benefit of taxane (allocation to EC/T rather than CEF) for patients classified as TLE3 +, compared with those who are TLE3 - , where classification as positive was based on a tumour having $>30 \%$ cells stained positive (Kulkarni et al, 2009). Prediction was assessed with a test of interaction between treatment and TLE3 classification.

Secondary objectives. Secondary aims were to explore whether there was a similar directional predictive effect for patients on the $\mathrm{AC} / \mathrm{T}$ arm, by way of TLE3 interaction with $\mathrm{AC} / \mathrm{T}$ and $\mathrm{CEF}$, as well as EC/T vs AC/T. Additionally, we planned to examine whether a Box-Cox variance stabilisation transformation should be considered for continuous (transformed) TLE3, and to examine the effects of continuous TLE and alternate categorisations (cut-points) of TLE3 on RFS.

Immunohistochemistry for TLE3. Standard immunohistochemical techniques were used to stain TMAs for TLE3 (Kulkarni et al, 2009). Assays were performed to good laboratory practice using single batches of each antibody and reagent; incubations were rigorously controlled for temperature. In each assay, quality controls were included as described previously (Bartlett et al, 2011). Staining for TLE3 was performed essentially as described previously using a Bondmax (Leica, Concord, ON, Canada) automated staining platform. TLE3 (1:2000, TLE3 Mouse monoclonal Antibody, Clarient, GE Healthcare, Aliso Viejo, CA, USA) was incubated at room temperature for $1 \mathrm{~h}$ before visualisation with a standard DAB protocol (see Supplementary Information). Glass slides were scanned using the (Leica) Ariol SL50 image analysis system (Bartlett et al, 2011) and the resultant digital images of each TMA core scored visually by highly trained observers (Kirkegaard et al, 2006) as well as separately by image analysis using a predefined algorithm on the Ariol SL50 system (see Supplementary Information). The percentage of cells staining positive for TLE3 was recorded for each of potentially four TMA cores. For automated image analysis, using a specifically designed Ariol Software 3.4.2 algorithm, the number of cells evaluated to have TLE3 stain was summed across all four cores and the absolute percentage positivity derived from the total cell count assessed per case. Cases were then regarded as positive (i) if there was at least one core with $>30 \%$ cells positive for TLE3, and in a separate analysis, (ii) if $>30 \%$ of all cells analysed were positive for TLE3.

Histoscores for each core (membrane staining only) were recorded. Visual scoring was performed by pathologists who had completed a training TMA with TLE3-stained breast cancers, and achieved high concordance in classification using the $30 \%$ positivity cut-point. For visual assessment, each core needed to have at least 50 evaluable tumour cells to be counted. A tumour was considered positive if there was at least one core with $>30 \%$ positive stain for TLE3; the continuous score was the average score in all cores.

Statistical design and analysis. Analyses were performed on intent-to-treat populations. We formally tested whether there were imbalances between the 1097 TMA patients and the 2104 patients 
in the MA.21 trial. Exact Fisher tests were used to examine whether there were imbalances by treatment arm or stratification factors. The final analysis data were used for these investigations.

The published 411 patient discovery cohort indicated that clinicopathologic factors did not impact TLE3 results, so we expected $58.6 \%$ of patients to be TLE3 + (Kulkarni et al, 2009). If patient experience in MA.21 was similar to that in the discovery cohort, then we would expect a HR for TLE3 + /TLE3 - of 0.1-0.2. We assumed the event rates for the TMA patients would be similar to those for the full trial with an approximately equal split of the 1097 TMA patients by arm. Then, the power for a two-sided 5\% alpha level TLE3 interaction test between patients with/without taxane would be close to $100 \%$ with the previous HR of 0.1 or a HR of 0.2 ; and with a HR of 0.5 , the power would be about $90 \%$.

With no evidence of significant imbalances, the univariate test was to be a stratified log-rank test. Exploratory multivariate analyses utilised step-wise forward Cox regression, where baseline patient and tumour characteristic factors were added if $P \leqslant 0.05$, with likelihood ratio criterion test statistic $\left(\sim \chi_{(1)}^{2}\right)$. Predictive effect was assessed multivariately with a test of interaction between treatment allocation and TLE3 status. Graphical description was with Kaplan-Meier plots.

TLE3 assessors were blinded to all clinical data. TLE3 and clinical data were held, and all analyses performed, by the NCIC CTG MA.21 trial statisticians. The TLE3 study team made the decision to publish the results. Manuscript writing was undertaken by the first author, co-authors, and faculty at the NCIC CTG central office, who vouch for the fidelity of the study and for accuracy and completeness of the data.

\section{RESULTS}

Patients. MA.21 randomised 2104 patients between 4 December 4 2000 and 29 April 29 2005: 701 to CEF; 701 to EC/T; 702 to AC/T. The analyses in this report utilised the final analysis database with a median follow-up of 8.0 years. Blocks were available for 1097 (52\%) of MA.21 patients and TLE3 assessed by at least one of the methods for 1038 (49\%) of MA.21 patients, with 59 (5\%) of tumour blocks not assessable by either method: 959 (46\%) of the patients were assessed visually for TLE3; 1035 (49\%) assessed by automated image analysis; 79 (7.6\%) of 1038 patients were not assessable visually, although assessed by automated image analysis; $3(0.3 \%)$ of 959 patients were assessable visually, although not by automated image analysis.

There were no significant imbalances by treatment arms or stratification factors between those assessed for TLE3, vs those not, for visual assessment and for automated image analysis (Supplementary Table 1). Relapse-free survival was not significantly different for those included or not in the TLE3 investigation: by visual assessment $(P=0.97)$ or automated image analysis $(P=0.81$; data not shown).

Immunohistochemical staining for TLE3. Of the 4388 cores (4 cores for each of 1097 cases), visual pathologic review indicated no tumour in 1196 (27\%) of cores, missing core in 212 (4.8\%) instances, and $192(4.3 \%)$ with fewer than 50 tumour cells/core. The mean number of cells for those cases counted and scored by automated imaged analysis was 934, with a median of 580 cells per case.

Histograms of TLE3 scores are provided (Supplementary Figure $1 \mathrm{~A}$ and $\mathrm{B}$ ); a Box-Cox transformation was not indicated for either assessment modality. Comparison of results from visual and automated scores (Supplementary Figure 2) indicated a strong association between results of the two scoring methods with Pearson and Spearman correlation coefficients, respectively, of 0.85 $(P<0.0001)$ and $0.83(P<0.0001)$. The proportion of TLE3 + patients ( $>30 \%$ stain) by treatment arm and assessment method is reported in Table 1. Globally, $83.2 \%$ of cases were positive by visual assessment. Meanwhile, $80.6 \%$ and $78.8 \%$ of cases were positive by automated image analysis, respectively, for results where at least one core has $>30 \%$ TLE3 stain or $>30 \%$ of all cells have TLE3 stain. Hereafter, the primary categorical TLE3 comparisons involves positivity defined by $>30 \%$ TLE3 stain in all cells assessed by image analysis, with similar results observed for those based on core(s).

Patient characterisation by baseline factors and TLE3 status. We examined the proportion of patients with TLE3 + and TLE3 - tumors (Table 1). For both visual and automated assessments, TLE3 positivity was highly associated with ERpositive tumours $(P<0.0001)$ and subsequent receipt of adjuvant endocrine therapy $(P<0.0001)$.

\section{Univariate results}

Visual IHC. There were no significant differences in RFS for those allocated EC/T or CEF by TLE3 status (Figure $1 \mathrm{~A} ; P=0.29$ ), although TLE3 + patients allocated EC/T had directionally better RFS experience than patients with TLE3 - tumours or than TLE3 + / - patients allocated CEF. For TLE3 + patients (Figure 1B), the HR of EC/T to CEF was 0.82 (95\% CI 0.54 to $1.24 ; P=0.34)$. Meanwhile, the outcome for TLE3 - tumours is shown in Figure 1C: the HR of EC/T to CEF is 0.55 (95\% CI 0.21 to $1.43 ; P=0.21)$. Exploratory investigations with quartile cut-points also indicated no significant univariate RFS differences for TLE3 + patients allocated EC/T or CEF (Supplementary Figure 3A, with first quartile cut-point, $P=0.91$; Supplementary Figure $3 B$, with median cut-point, $P=0.91$ ).

Automated image analysis IHC. Similar results were obtained with automated image analysis. There were no significant differences in RFS based on TLE3 status and allocation to EC/T or CEF (Figure 2A; $P=0.18$ ). For TLE3 + tumours (Figure 2B), the HR for patients allocated EC/T compared with those allocated CEF was 0.84 (95\% CI 0.56 to 1.26 ; $P=0.40)$; however, that for TLE3 - tumours was 0.50 (95\% CI 0.22 to $1.16 ; P=0.10$, Figure $2 \mathrm{C}$ ). Quartile cut-points again indicated no significant univariate effect of treatment allocation for TLE3 + patients on RFS (Supplementary Figure $4 \mathrm{~A}$, with first quartile cut-point, $P=0.56$; Supplementary Figure $4 \mathrm{~B}$, with median cut-point, $P=0.83$ ).

\section{Multivariate results}

Visual IHC. As in the MA.21 trial, patients allocated to EC/T and CEF did not have significantly different RFS (HR $=0.84$ (95\% CI 0.33 to $2.12 ; P=0.72$, Table 2)). TLE3 + tumours were not associated with either a prognostic effect on $\mathrm{RFS}(\mathrm{HR}=0.95$ (95\% CI 0.49 to $1.82 ; P=0.87)$ ) or a predictive effect $(P=0.68)$. Patients on CEF regimen who received adjuvant endocrine therapy had significantly improved RFS ( $\mathrm{HR}=0.17$ (95\% CI 0.08 to 0.38 ; $P<0.0001)$ ), whereas those who received anti-Her2 therapy had significantly shorter RFS ( $\mathrm{HR}=3.63 \quad(95 \%$ CI 1.82 to 7.25 ; $P=0.0003)$ ). Continuous values of TLE3 did not have a significant multivariate effect on RFS $(P>0.05)$.

Automated image analysis IHC. Similar multivariate results were seen with automated image analysis (Table 2): EC/T and CEF patients experienced similar RFS ( $\mathrm{HR}=0.60$ (95\% CI 0.26 to 1.36 ; $P=0.22)$ ); again, having a TLE3 + tumour was not associated with a prognostic impact on RFS (HR $=0.79$ (95\% CI 0.45 to 1.39 ; $P=0.42)$, nor a predictive effect $(P=0.44)$. Patients on CEF regimen who received adjuvant endocrine therapy had significantly improved RFS $(\mathrm{HR}=0.23$ (95\% CI 0.11 to $0.49 ; P=0.0001)$ ), whereas those who received anti-Her2 therapy had significantly shorter RFS (HR=1.42 (95\% CI 0.58 to $3.43 ; P=0.0003)$ ). 
Table 1. Characterisation of TLE3 status by baseline clinic-pathological features

\begin{tabular}{|c|c|c|c|c|c|c|c|}
\hline Factor & Category & $\begin{array}{c}\text { Visual IHC TLE3 - } \\
(n=161)\end{array}$ & $\begin{array}{l}\text { Visual TLE3 }+ \\
\quad(n=798)\end{array}$ & $P$-value ${ }^{a}$ & $\begin{array}{l}\text { Ariol TLE3 - } \\
\quad(n=201)\end{array}$ & $\begin{array}{l}\text { Ariol TLE3 }+ \\
\quad(n=834)\end{array}$ & $P$-value ${ }^{a}$ \\
\hline Treatment & $\begin{array}{c}\mathrm{EC} / \mathrm{T} \\
\mathrm{CEF} \\
\mathrm{AC} / \mathrm{T}\end{array}$ & $\begin{array}{l}41 \text { (12.9\%) } \\
62 \text { (18.2\%) } \\
58 \text { (19.2\%) }\end{array}$ & $\begin{array}{l}276(87.1 \%) \\
278(81.8 \%) \\
244(80.8 \%)\end{array}$ & 0.076 & $\begin{array}{l}58 \text { (16.8\%) } \\
73 \text { (19.9\%) } \\
70 \text { (21.6\%) }\end{array}$ & $\begin{array}{l}287(83.2 \%) \\
293(80.1 \%) \\
254(78.4 \%)\end{array}$ & 0.279 \\
\hline Age & $\begin{array}{l}<=39 \\
60-69 \\
50-59 \\
40-49\end{array}$ & $\begin{array}{c}16(11.0 \%) \\
0(0.0 \%) \\
61(17.3 \%) \\
84(18.8 \%)\end{array}$ & $\begin{array}{c}129 \text { (89.0\%) } \\
15 \text { (100\%) } \\
291 \text { (82.7\%) } \\
363(81.2 \%)\end{array}$ & 0.050 & $\begin{array}{c}23(14.5 \%) \\
0(0.0 \%) \\
92(24.1 \%) \\
86(18.0 \%)\end{array}$ & $\begin{array}{c}136(85.5 \%) \\
16(100 \%) \\
290(75.9 \%) \\
392(82.0 \%)\end{array}$ & 0.006 \\
\hline Race & $\begin{array}{c}\text { White } \\
\text { Unknown } \\
\text { Hawiian/Pacific } \\
\text { Black } \\
\text { Asian } \\
\text { Aboriginal }\end{array}$ & $\begin{array}{c}148 \text { (16.8\%) } \\
4(21.1 \%) \\
0 \text { (0.0\%) } \\
2(10.0 \%) \\
5(19.2 \%) \\
2(18.2 \%)\end{array}$ & $\begin{array}{r}734 \text { (83.2\%) } \\
15 \text { (78.9\%) } \\
1 \text { (100\%) } \\
18(90.0 \%) \\
21(80.8 \%) \\
9(81.8 \%)\end{array}$ & 0.941 & $\begin{array}{c}184 \text { (19.5\%) } \\
7 \text { (33.3\%) } \\
0 \text { (0.0\%) } \\
5 \text { (20.0\%) } \\
4(12.9 \%) \\
1 \text { (9.1\%) }\end{array}$ & $\begin{array}{c}762(80.5 \%) \\
14(66.7 \%) \\
1(100 \%) \\
20(80.0 \%) \\
27(87.1 \%) \\
10(90.9 \%)\end{array}$ & 0.488 \\
\hline Performance status & $\begin{array}{l}2 \\
1 \\
0\end{array}$ & $\begin{array}{r}2(50.0 \%) \\
35(19.8 \%) \\
124(15.9 \%)\end{array}$ & $\begin{array}{r}2(50.0 \%) \\
142(80.2 \%) \\
654(84.1 \%)\end{array}$ & 0.096 & $\begin{array}{r}1(25.0 \%) \\
37(19.6 \%) \\
163(19.4 \%)\end{array}$ & $\begin{array}{r}3(75.0 \%) \\
152(80.4 \%) \\
679(80.6 \%)\end{array}$ & 0.959 \\
\hline Type of surgery & $\begin{array}{l}\text { Total mastectomy } \\
\text { Partial mastectomy }\end{array}$ & $\begin{array}{l}80(17.2 \%) \\
81(16.4 \%)\end{array}$ & $\begin{array}{l}386(82.8 \%) \\
412(83.6 \%)\end{array}$ & 0.760 & $\begin{array}{r}99(19.8 \%) \\
102(19.1 \%)\end{array}$ & $\begin{array}{l}401(80.2 \%) \\
433(80.9 \%)\end{array}$ & 0.765 \\
\hline Number of positive nodes & $\begin{array}{c}>10 \\
4-10 \\
1-3 \\
0\end{array}$ & $\begin{array}{l}10 \text { (17.2\%) } \\
37 \text { (17.9\%) } \\
51 \text { (12.8\%) } \\
63 \text { (21.4\%) }\end{array}$ & $\begin{array}{r}42 \text { (82.8\%) } \\
170 \text { (82.1\%) } \\
348 \text { (87.2\%) } \\
232 \text { (78.6\%) }\end{array}$ & 0.027 & $\begin{array}{r}8 \text { (13.3\%) } \\
49 \text { (21.8\%) } \\
77 \text { (17.7\%) } \\
67 \text { (21.3\%) }\end{array}$ & $\begin{array}{r}52(86.7 \%) \\
176(78.2 \%) \\
358(82.3 \%) \\
248(78.7 \%)\end{array}$ & 0.292 \\
\hline T stage & $\begin{array}{l}\text { Tx } \\
\text { T4 } \\
\text { T3 } \\
\text { T2 } \\
\text { T1 }\end{array}$ & $\begin{array}{c}2 \text { (66.7\%) } \\
0(0.0 \%) \\
15(16.7 \%) \\
102(19.0 \%) \\
42(13.2 \%)\end{array}$ & $\begin{array}{c}1 \text { (33.3\%) } \\
13 \text { (100\%) } \\
75 \text { (83.3\%) } \\
434 \text { (81.0\%) } \\
275 \text { (86.8\%) }\end{array}$ & 0.013 & $\begin{array}{c}2 \text { (66.7\%) } \\
0(0.0 \%) \\
19(19.6 \%) \\
115(20.1 \%) \\
65(18.7 \%)\end{array}$ & $\begin{array}{c}1(33.3 \%) \\
15(100 \%) \\
78(80.4 \%) \\
457(79.9 \%) \\
283(81.3 \%)\end{array}$ & 0.085 \\
\hline Nodal status & $\begin{array}{l}\text { N2 } \\
\text { N1 } \\
\text { N0 }\end{array}$ & $\begin{array}{r}9 \text { (14.3\%) } \\
89 \text { (14.8\%) } \\
63(21.3 \%)\end{array}$ & $\begin{array}{r}54 \text { (85.7\%) } \\
511(85.2 \%) \\
233(78.7 \%\end{array}$ & 0.045 & $\begin{array}{r}14(20.0 \%) \\
119(18.3 \%) \\
68(21.5 \%)\end{array}$ & $\begin{array}{r}56(80.0 \%) \\
530(81.7 \%) \\
248(78.5 \%)\end{array}$ & 0.499 \\
\hline ER status & $\begin{array}{l}\text { Positive } \\
\text { Negative }\end{array}$ & $\begin{array}{c}50(8.8 \%) \\
111(28.6 \%)\end{array}$ & $\begin{array}{l}521(91.2 \%) \\
277(71.4 \%)\end{array}$ & $<0.0001$ & $\begin{array}{r}77(12.7 \%) \\
124(29.0 \%)\end{array}$ & $\begin{array}{l}530(87.3 \%) \\
304(71.0 \%)\end{array}$ & $<0.0001$ \\
\hline Menopausal status & $\begin{array}{l}\text { Pre } \\
\text { Post }\end{array}$ & $\begin{array}{r}112(16.9 \%) \\
49(16.4 \%)\end{array}$ & $\begin{array}{l}549(83.1 \%) \\
249(83.6 \%\end{array}$ & 0.848 & $\begin{array}{r}130(18.2 \%) \\
71(22.1 \%)\end{array}$ & $\begin{array}{l}584(81.8 \%) \\
250(77.9 \%)\end{array}$ & 0.141 \\
\hline HER2 status & $\begin{array}{l}\text { Unknown } \\
\text { Positive } \\
\text { Negative } \\
3+ \\
2+ \\
0 \text { or } 1+\end{array}$ & $\begin{array}{r}26(16.0 \%) \\
2(14.3 \%) \\
3(14.3 \%) \\
8(8.1 \%) \\
12(17.9 \% \\
110(18.5 \%)\end{array}$ & $\begin{array}{r}137(84.0 \%) \\
12(85.7 \%) \\
18(85.7 \%) \\
91(91.9 \%) \\
55(82.1 \%) \\
485(81.5 \%)\end{array}$ & 0.228 & $\begin{array}{r}31(18.0 \%) \\
3(21.4 \%) \\
7(31.8 \%) \\
14(13.3 \%) \\
16(22.2 \%) \\
130(20.0 \%)\end{array}$ & $\begin{array}{r}141(82.0 \%) \\
11(78.6 \%) \\
15(68.2 \%) \\
91(86.7 \%) \\
56(77.8 \%) \\
520(80.0 \%)\end{array}$ & 0.369 \\
\hline Adjuvant Rx & $\begin{array}{c}\text { Yes } \\
\text { No } \\
\text { Missing }\end{array}$ & $\begin{array}{c}116(16.5 \%) \\
45 \text { (17.9\%) } \\
0 \text { (0.0\%) }\end{array}$ & $\begin{array}{c}587(83.5 \%) \\
206(82.1 \%) \\
5(100 \%)\end{array}$ & 0.604 & $\begin{array}{r}142(18.8 \%) \\
58(21.2 \%) \\
1(20.0 \%)\end{array}$ & $\begin{array}{r}615 \text { (81.2\%) } \\
215 \text { (78.8\%) } \\
4(80.0 \%)\end{array}$ & 0.373 \\
\hline Adjuvant Endo & $\begin{array}{c}\text { Yes } \\
\text { No } \\
\text { Missing }\end{array}$ & $\begin{array}{c}49 \text { (87\%) } \\
112(28.8 \%) \\
0(0.0 \%)\end{array}$ & $\begin{array}{c}516(91.3 \%) \\
277(71.2 \%) \\
5(100 \%)\end{array}$ & $<0.0001$ & $\begin{array}{r}77(12.8 \%) \\
123(28.8 \%) \\
1(20.0 \%)\end{array}$ & $\begin{array}{r}526(87.2 \%) \\
304(71.2 \%) \\
4(80.0 \%)\end{array}$ & $<0.0001$ \\
\hline Adjuvant Herceptin & $\begin{array}{c}\text { Yes } \\
\text { No } \\
\text { Missing }\end{array}$ & $\begin{array}{r}10(16.9 \%) \\
151(16.9 \%) \\
0(0.0 \%)\end{array}$ & $\begin{array}{r}49(83.1 \%) \\
744(83.1 \%) \\
5(100 \%)\end{array}$ & 0.988 & $\begin{array}{r}13(20.6 \%) \\
187(19.3 \%) \\
1(20.0 \%)\end{array}$ & $\begin{array}{r}50(79.4 \%) \\
780(80.7 \%) \\
4(80.0 \%)\end{array}$ & 0.801 \\
\hline Histologic Grade III & $\begin{array}{c}\text { Yes } \\
\text { No } \\
\text { Missing }\end{array}$ & $\begin{array}{l}93(20.7 \%) \\
23(11.1 \%) \\
45(14.9)\end{array}$ & $\begin{array}{l}357(79.3 \%) \\
184(88.9 \%) \\
257(85.1)\end{array}$ & 0.006 & $\begin{array}{c}115(23.9 \%) \\
27(11.8 \%) \\
59(18.2)\end{array}$ & $\begin{array}{l}366(76.1 \%) \\
202(88.2 \%) \\
266(81.8)\end{array}$ & 0.001 \\
\hline
\end{tabular}



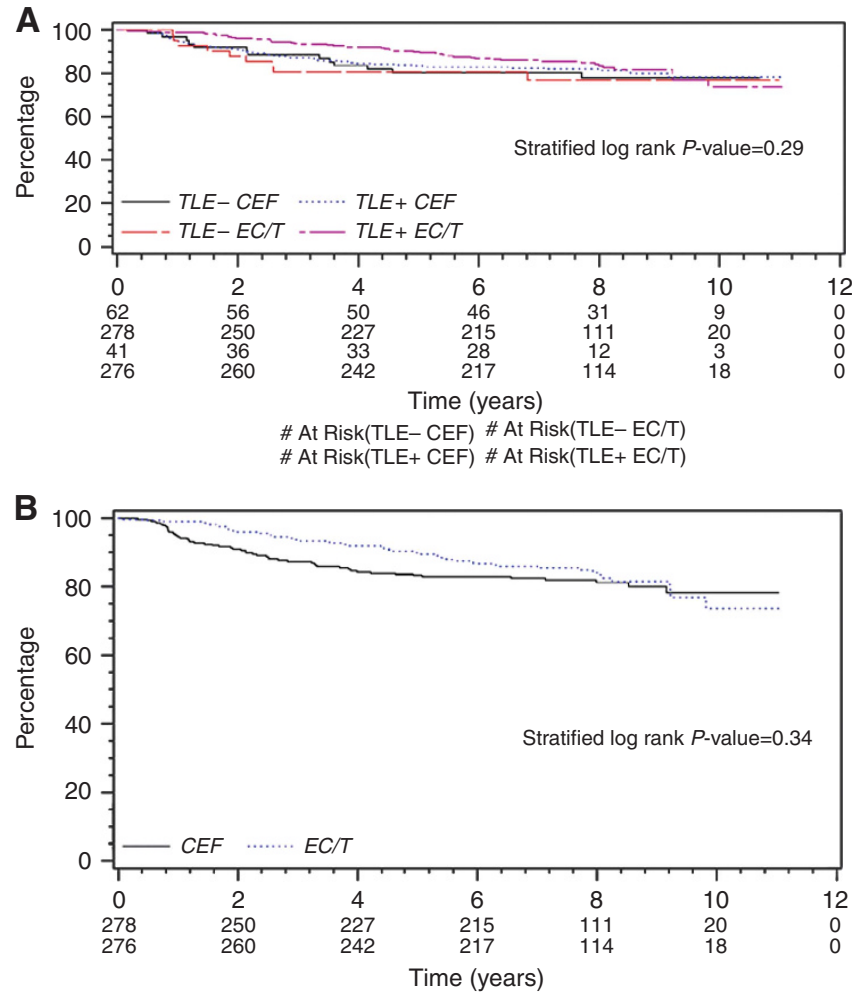

\# At Risk(CEF) \# At Risk(EC/T)

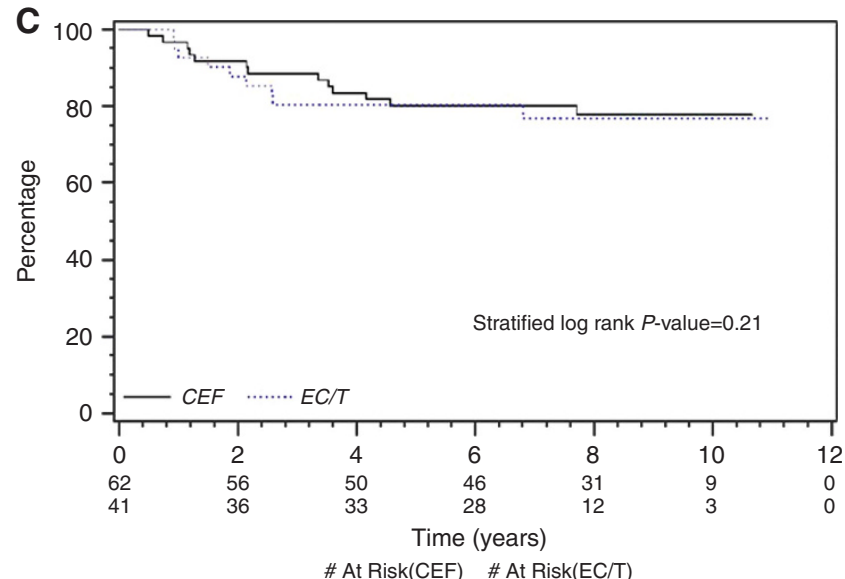

Figure 1. Visually assessed TLE3 staining and outcome by treatment arm. (A) Recurrence-free survival by Visual TLE3: Status stratified by allocation to EC/T or CEF: TLE - CEF = patients with $<30 \%$ TLE3 tumour-positive cells allocated to CEF arm. TLE3 + CEF = patients with $\geqslant 30 \%$ TLE3 tumour-positive cells allocated to CEF arm. TLE - EC/ $\mathrm{T}=$ patients with $<30 \%$ TLE3 tumour-positive cells allocated to $\mathrm{EC} / \mathrm{T}$ arm. TLE3 $+E C / T=$ patients with $\geqslant 30 \%$ TLE3 tumour-positive cells allocated to EC/T arm. (B) Recurrence-free survival for TLE3-positive cases by Visual TLE3: Status stratified by allocation to EC/T or CEF: $\mathrm{CEF}=$ patients allocated to $\mathrm{CEF}$ arm. $E C / T$ = patients allocated to $E C / T$ arm. (C) Recurrence-free survival for TLE3-negative cases by Visual TLE3: Status stratified by allocation to $E C / T$ or $C E F$ : $C E F=$ patients allocated to $C E F$ arm. $E C / T$ = patients allocated to $E C / T$ arm.

Continuous values of TLE3 did not have a significant multivariate association with RFS $(P>0.05)$.

Taxane as administered in the AC/T regimen of MA.21. The MA.21 AC/T regimen was significantly inferior to CEF in both the main trial and this investigation, and remained inferior (univariate, $P=0.01$ ) within the TLE3 + populations when TLE3 was assessed visually or by automation.

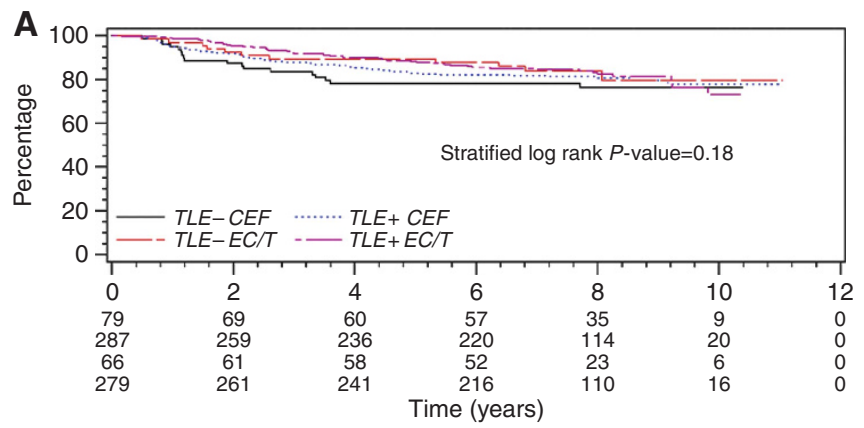

\# At Risk(TLE- CEF) \# At Risk(TLE- EC/T) \# At Risk(TLE+ CEF) \# At Risk(TLE+ EC/T)

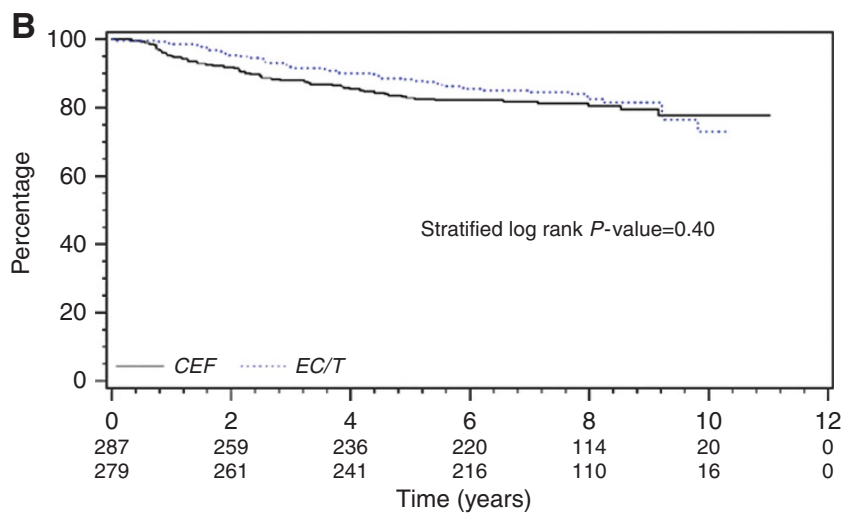

\# At Risk(CEF) \# At Risk(EC/T)

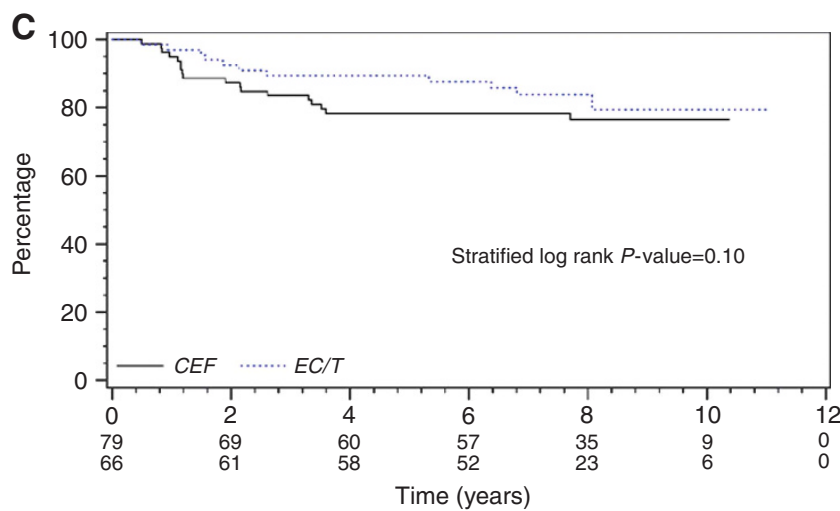

\# At Risk(CEF) \# At Risk(EC/T)

Figure 2. Image analysis of TLE3 staining and outcome by treatment arm. (A) Recurrence-free survival by Image analysis of TLE3: Status stratified by allocation to EC/T or CEF: TLE - CEF = patients with $<30 \%$ TLE3 tumour-positive cells allocated to CEF arm. TLE3 + $\mathrm{CEF}=$ patients with $\geqslant 30 \%$ TLE3 tumour-positive cells allocated to CEF arm. TLE $-E C / T=$ patients with $<30 \%$ TLE3 tumour-positive cells allocated to EC/T arm. TLE3 + EC/T=patients with $\geqslant 30 \%$ TLE3 tumour-positive cells allocated to EC/T arm. (B) Recurrence-free survival for TLE3-positive cases by image analysis of TLE3: Status stratified by allocation to $\mathrm{EC} / \mathrm{T}$ or $\mathrm{CEF}: \mathrm{CEF}=$ patients allocated to $\mathrm{CEF}$ arm. $E C / T=$ patients allocated to $E C / T$ arm. (C) Recurrence-free survival for TLE3 negative cases by image analysis TLE3: Status stratified by allocation to $E C / T$ or $C E F: C E F=$ patients allocated to $C E F$ arm. $E C / T$ p patients allocated to $E C / T$ arm.

\section{DISCUSSION}

In a large, prospectively planned analysis within the NCIC CTG MA21 study, we found no evidence, using a previously validated protocol for IHC staining and analysis, that TLE3 acts as a predictive biomarker for taxane benefit in early breast cancer. 
Table 2. RFS stratified step-wise multivariate Cox model with TLE3 cut-point of $30 \%$

\begin{tabular}{|c|c|c|c|}
\hline Visual IHC factor & Hazard ratio & $95 \% \mathrm{Cl}$ & $P$-value ${ }^{a}$ \\
\hline Treatment (Trt) EC/T vs CEF & 0.84 & $0.33-2.12$ & 0.715 \\
\hline TLE3 + vs TLE3 - & 0.95 & $0.49-1.82$ & 0.869 \\
\hline Endocrine therapy & 0.17 & $0.08-0.38$ & $<0.0001$ \\
\hline Anti-HER2 therapy & 3.63 & $1.82-7.25$ & 0.0003 \\
\hline Interaction of TLE3 and Trt & 0.81 & $0.29-2.24$ & 0.682 \\
\hline $\begin{array}{l}\text { Interaction of endocrine therapy } \\
\text { and Trt }\end{array}$ & 1.91 & $0.86-4.24$ & 0.114 \\
\hline $\begin{array}{l}\text { Interaction of anti-HER2 therapy } \\
\text { and Trt }\end{array}$ & 0.57 & $0.16-2.07$ & 0.393 \\
\hline \multicolumn{4}{|l|}{ Ariol Image analysis } \\
\hline \multicolumn{4}{|l|}{ Factor } \\
\hline $\begin{array}{l}\text { Trt EC/T vs CEF } \\
\text { TLE3 + vs TLE3 - } \\
\text { Endocrine therapy } \\
\text { Anti-HER2 therapy } \\
\text { Interaction of TLE3 and Trt } \\
\text { Interaction of endocrine } \\
\text { therapy and Trt } \\
\text { Interaction of anti-HER2 } \\
\text { therapy and Trt }\end{array}$ & $\begin{array}{l}0.60 \\
0.79 \\
0.23 \\
3.40 \\
1.42 \\
1.38 \\
\\
\\
0.56\end{array}$ & $\begin{array}{l}0.26-1.36 \\
0.45-1.39 \\
0.11-0.49 \\
1.77-6.56 \\
0.58-3.43 \\
0.65-2.90 \\
0.16-1.98\end{array}$ & $\begin{array}{l}0.219 \\
0.416 \\
0.0001 \\
0.0003 \\
0.443 \\
0.402 \\
\\
0.360\end{array}$ \\
\hline \multicolumn{4}{|c|}{$\begin{array}{l}\text { Abbreviations: } 95 \% \mathrm{Cl}=95 \% \text { confidence interval; } \mathrm{IHC}=\text { immunohistochemistry; } \mathrm{RFS}= \\
\text { relapse-free survival; Trt }=\text { Treatment; Visual } I \mathrm{HC}=\mathrm{TLE} 3 \text { staining assessed visually. Ariol } \\
\text { image analysis }=\mathrm{TLE} 3 \text { staining assessed using automated image analysis. } \\
{ }^{a} \text {-value is based on Wald statistic. }\end{array}$} \\
\hline
\end{tabular}

Using identical methods for the staining and evaluation of TLE3 expression to those used in previous studies (Samimi et al, 2012) in almost 1100 breast cancer samples from a prospective randomised clinical trial, no evidence of a statistically significant treatment by marker interaction between TLE3 and taxane containing chemotherapy was observed. This evidence contrasts with previous studies in early breast cancer with smaller sample sizes (Kulkarni et al, 2009) and with larger retrospective cohort studies of lung and ovarian cancer patients.

In addition to the preplanned analysis, we performed exploratory analyses using additional thresholds for TLE3 positivity in order to explore the possibility that the predetermined cut-point for TLE3 might poorly reflect the potential of this marker to identify patients likely to benefit from taxane therapy. In univariate analyses, unadjusted and stratified by lymph node status, ER status, and type of surgery, there was no significant evidence that TLE3 acts as a marker of taxane benefit, although the HR for taxane benefit was consistently lower for TLE3 - than for TLE3 + cases (Figures 1 and 2). This observation, however, is contrary to the primary hypothesis that increased TLE3 activity is associated with response to taxane-based chemotherapy. When multivariate analyses were performed, including the treatment by marker interaction for TLE3 and taxane therapy with the prognostic effect of TLE3 and the treatment effect, there was no evidence that TLE3 was acting as a potential predictive marker of taxane benefit in this study. The observed effects were explained by the treatment effect and a potential for TLE3 to identify prognostic/residual risk effects but not to act as a predictive biomarker (see Table 3). Nor was there any evidence to inform selection of the optimal cut-offsimilar effects were observed when cases were divided by the lower and upper quartiles and the median TLE3 expression levels (Supplementary Figures 3 and 4).

Despite careful standardisation of staining and scoring methods to match those of the previous hypothesis-generating studies (Kulkarni et al, 2009), a markedly greater proportion of breast cancers were identified as TLE3+ in the current study. This cannot be easily explained by differences in patient demographics or disease characteristics, and may reflect limitations
Table 3. RFS stratified step-wise multivariate Cox model with TLE3 median cut-point

\begin{tabular}{|c|c|c|c|}
\hline Visual IHC factor & Hazard ratio & $95 \% \mathrm{Cl}$ & $P$-value ${ }^{a}$ \\
\hline Treatment (Trt) EC/T vs CEF & 0.72 & $0.39-1.31$ & 0.278 \\
\hline TLE3 + vs TLE3 - & 0.76 & $0.44-1.31$ & 0.320 \\
\hline Endocrine therapy & 0.18 & $0.08-0.40$ & $<0.0001$ \\
\hline Anti-HER2 therapy & 3.64 & $1.83-7.26$ & 0.0002 \\
\hline Interaction of TLE3 andTrt & 1.02 & $0.47-2.24$ & 0.957 \\
\hline $\begin{array}{l}\text { Interaction of endocrine therapy } \\
\text { and Trt }\end{array}$ & 1.82 & $0.81-4.10$ & 0.147 \\
\hline $\begin{array}{l}\text { Interaction of anti-HER2 therapy } \\
\text { and Trt }\end{array}$ & 0.58 & $0.15-2.07$ & 0.400 \\
\hline \multicolumn{4}{|l|}{ Ariol Image analysis } \\
\hline \multicolumn{4}{|l|}{ Factor } \\
\hline $\begin{array}{l}\text { Trt EC/T vs CEF } \\
\text { TLE3 + vs TLE3 - } \\
\text { Endocrine therapy } \\
\text { Anti-HER2 therapy } \\
\text { Interaction of TLE3 and Trt } \\
\text { Interaction of endocrine } \\
\text { therapy and Trt } \\
\text { Interaction of anti-HER2 } \\
\text { therapy and Trt }\end{array}$ & $\begin{array}{l}0.75 \\
0.77 \\
0.23 \\
3.30 \\
1.10 \\
1.41 \\
\\
\\
0.57\end{array}$ & $\begin{array}{l}0.42-1.34 \\
0.46-1.28 \\
0.11-0.50 \\
1.71-6.38 \\
0.52-2.31 \\
0.66-3.02 \\
0.17-1.99\end{array}$ & $\begin{array}{l}0.330 \\
0.308 \\
0.0002 \\
0.0004 \\
0.809 \\
0.379 \\
\\
0.380\end{array}$ \\
\hline \multicolumn{4}{|c|}{$\begin{array}{l}\text { Abbreviations: } 95 \% \mathrm{Cl}=95 \% \text { confidence interval; } I \mathrm{HC}=\text { immunohistochemistry; } \mathrm{RFS}= \\
\text { relapse-free survival; } \mathrm{Trt}=\text { Treatment; Visual } I \mathrm{HC}=\mathrm{TLE} 3 \text { staining assessed visually. Ariol } \\
\text { image analysis = TLE3 staining assessed using automated image analysis. } \\
\mathrm{a}_{P \text {-value is based on Wald statistic. }}\end{array}$} \\
\hline
\end{tabular}

in the analytical validity of TLE3 immunohistochemistry on clinical specimens. In addition, the relatively poor outcome of the $\mathrm{AC} / \mathrm{T}$ arm of the trial necessitated restriction of the prognostic/ predictive impact of TLE3 to the direct comparison between only two of the three arms of the MA21 trial (EC/T vs CEF). Despite these effects, which eroded the statistical power of the primary, predefined analysis, exploratory analyses failed to identify any cutpoint or situation in which TLE3 might act as a predictive biomarker of taxane benefit. The CEF vs EC/T randomisation in MA21 represents a taxane substitution; assessment of trials with other designs would be needed to address the potential predictive value of TLE3 for taxane addition (Bedard et al, 2010). Another small study (28 cases) of neoadjuvant therapy also failed to validate TLE3 (Susini et al, 2014)

This study represents a formal prospective-retrospective analysis of a randomised clinical trial with a prespecified classifier, and so represents a higher level of evidence (Simon et al, 2009) than the hypothesis generating preliminary studies that inspired this analysis. In this context, the negative result we obtained (failure to support the hypothesis) is perhaps not surprising, but it remains critical that studies such as this one be undertaken and published to counteract the publication bias that would otherwise result in the literature (Hopewell et al, 2009).

In conclusion, in this large, prospectively powered and planned analysis, no evidence to support the hypothesis that TLE3 is a predictive biomarker for taxane benefit was observed. Alternative strategies to select patients who may benefit from taxane-based chemotherapy should be pursued.

\section{ACKNOWLEDGEMENTS}

This study was conducted with the support of the Ontario Institute for Cancer Research through funding provided by the Government of Ontario and Clarient. Funding for NCIC CTG MA.21 was provided by the Canadian Cancer Society Research Institute by a grant to NCIC Clinical Trials Group \#015761, by the US NIH grant 
\#2U10CA077202, and by Amgen, Bristol-Myers Squibb, JanssenOrtho, Ortho Biotech, and Pfizer.

\section{CONFLICT OF INTEREST}

John Bartlett, Judy-Anne Chapman and Torsten Nielsen received research support from Clarient for this work. All other authors have no relevant conflicts of interest.

\section{REFERENCES}

Allen T, van TM, Iyengar P, Jothy S, Post M, Tsao MS, Lobe CG (2006) Grg1 acts as a lung-specific oncogene in a transgenic mouse model. Cancer Res 66(3): 1294-1301.

Bartlett JM, A'Hern R, Piper T, Ellis IO, Dowsett M, Mallon EA, Cameron DA, Johnston S, Bliss JM, Ellis P, Barrett-Lee PJ (2013) Phosphorylation of AKT pathway proteins is not predictive of benefit of taxane therapy in early breast cancer. Breast Cancer Res Treat 138(3): 773-781.

Bartlett JMS, Brookes CL, Robson T, van de Velde CJH, Billingham LJ, Campbell FM, Grant M, Hasenburg A, Hille ET, Kay C, Kieback DG, Putter H, Markopoulos C, Kranenbarg EM, Mallon EA, Dirix L, Seynaeve C, Rea D (2011) Estrogen receptor and progesterone receptor as predictive biomarkers of response to endocrine therapy: a prospectively powered pathology study in the Tamoxifen and Exemestane Adjuvant Multinational Trial. J Clin Oncol 29(12): 1531-1538.

Basu GD, Ghazalpour A, Arguello D, Ashfaq R, Gatalica Z, McGinniss MJ, Blevins R, Danenberg KD (2012) Frequency of TLE3 over-expression in breast carcinoma subtypes including a large cohort of triple negative patients. J Clin Oncol. In 2012 ASCO Annual Meeting Alexandria, VA, USA.

Bedard PL, Di Leo A, Piccart-Gebhart MJ (2010) Taxanes: optimizing adjuvant chemotherapy for early-stage breast cancer. Nat Rev Clin Oncol 7(1): $22-36$

Burnell M, Levine MN, Chapman JA, Bramwell V, Gelmon K, Walley B, Vandenberg T, Chalchal H, Albain KS, Perez EA, Rugo H, Pritchard K, O’Brien P, Shepherd LE (2010) Cyclophosphamide, epirubicin, and fluorouracil versus dose-dense epirubicin and cyclophosphamide followed by paclitaxel versus doxorubicin and cyclophosphamide followed by paclitaxel in node-positive or high-risk node-negative breast cancer. J Clin Oncol 28(1): 77-82.

Burnell M, Shepherd L, Gelmon K, Bramwell V, Walley B, Vandenberg T, Chalchal H, Pritchard K, Whelan T, Albain K, Perez E, Rugo H, O’Brien P, Chapman J, Levine M (2012) A randomized trial of CEF versus dose dence EC followed by paclitaxel versus AC followed by paclitaxel in women with node positive or high risk node negative breast cancer, NCIC CTG MA.21: Results of the final relapse free survival analysis. Cancer Res 72(24 Suppl): 194s-195s.

Hayes DF, Thor AD, Dressler LG, Weaver D, Edgerton S, Cowan D, Broadwater G, Goldstein LJ, Martino S, Ingle JN, Henderson IC, Norton L, Winer EP, Hudis CA, Ellis MJ, Berry DA (2007) HER2 and response to paclitaxel in node-positive breast cancer. New Engl J Med 357(15): 1496-1506.

Hopewell S, Loudon K, Clarke MJ, Oxman AD, Dickersin K (2009)

Publication bias in clinical trials due to statistical significance or direction of trial results. Cochrane Database Syst Rev. (1): MR000006.

Kirkegaard T, Edwards J, Tovey S, McGlynn LM, Krishna SN, Mukherjee R, Tam L, Munro AF, Dunne B, Bartlett JM (2006) Observer variation in immunohistochemical analysis of protein expression, time for a change? Histopathology 48(7): 787-794.

Kulkarni SA, Hicks DG, Watroba NL, Murekeyisoni C, Hwang H, Khoury T, Beck RA, Ring BZ, Estopinal NC, Schreeder MT, Seitz RS, Ross DT (2009) TLE3 as a candidate biomarker of response to taxane therapy. Breast Cancer Res 11(2): R17.

Lai D, Ho KC, Hao Y, Yang X (2011) Taxol resistance in breast cancer cells is mediated by the hippo pathway component TAZ and its downstream transcriptional targets Cyr61 and CTGF. Cancer Res 71(7): 2728-2738.
Leon C, Lobe CG (1997) Grg3, a murine Groucho-related gene, is expressed in the developing nervous system and in mesenchyme-induced epithelial structures. Dev Dyn 208(1): 11-24.

Leyland-Jones BR, Ambrosone CB, Bartlett J, Ellis MJC, Enos RA, Raji A, Pins MR, Zujewski JA, Hewitt SM, Forbes JF, Abramovitz M, Braga S, Cardoso F, Harbeck N, Denkert C, Jewell SD (2008) Recommendations for collection and handling of specimens from group breast cancer clinical trials. J Clin Oncol 26(34): 5638-5644.

Liu Y, Dehni G, Purcell KJ, Sokolow J, Carcangiu ML, Artavanis-Tsakonas S, Stifani S (1996) Epithelial expression and chromosomal location of human TLE genes: implications for notch signaling and neoplasia. Genomics 31(1): 58-64.

Metzger DE, Gasperowicz M, Otto F, Cross JC, Gradwohl G, Zaret KS (2012) The transcriptional co-repressor Grg3/Tle3 promotes pancreatic endocrine progenitor delamination and beta-cell differentiation. Development 139(8): 1447-1456.

Nakaya HI, Beckedorff FC, Baldini ML, Fachel AA, Reis EM, VerjovskiAlmeida S (2007) Splice variants of TLE family genes and up-regulation of a TLE3 isoform in prostate tumors. Biochem Biophys Res Commun 364(4): 918-923.

Peto R, Davies C, Godwin J, Gray R, Pan HC, Clarke M, Cutter D, Darby S, McGale P, Taylor C, Wang YC, Bergh J, Di LA, Albain K, Swain S, Piccart M, Pritchard K (2012) Comparisons between different polychemotherapy regimens for early breast cancer: meta-analyses of long-term outcome among 100,000 women in 123 randomised trials. Lancet 379(9814): $432-444$.

Pusztai L (2007) Markers predicting clinical benefit in breast cancer from microtubule-targeting agents. Ann Oncol 18(Suppl 12): xii15-xii20.

Rimm DL, Nielsen TO, Jewell SD, Rohrer DC, Broadwater G, Waldman F, Mitchell KA, Singh B, Tsongalis GJ, Frankel WL, Magliocco AM, Lara JF, Hsi ED, Bleiweiss IJ, Badve SS, Chen B, Ravdin PM, Schilsky RL, Thor A, Berry DA (2011) Cancer and Leukemia Group B Pathology Committee guidelines for tissue microarray construction representing multicenter prospective clinical trial tissues. J Clin Oncol 29(16): 2282-2290.

Ross DT, Seitz RS, Ring BZ, Wang Y, Beck RA, Sotlermann A (2010) TLE3 expression is predictive of response to chemotherapy in NSCLC. In Proceedings of the 101st Annual Meeting of the American Association for Cancer Research; 17-21 April 2010 Washington DC, USA.

Samimi G, Ring BZ, Ross DT, Seitz RS, Sutherland RL, O'Brien PM, Hacker NF, Huh WK (2012) TLE3 expression is associated with sensitivity to taxane treatment in ovarian carcinoma. Cancer Epidemiol Biomarkers Prev 21(2): 273-279.

Shon W, Jenkins SM, Ross DT, Seitz RS, Beck RA, Ring BZ, Okuno SH, Gibson LE, Folpe AL (2011) Angiosarcoma: a study of 98 cases with immunohistochemical evaluation of TLE3, a recently described marker of potential taxane responsiveness. J Cutan Pathol 38(12): 961-966.

Simon RM, Paik S, Hayes DF (2009) Use of archived specimens in evaluation of prognostic and predictive biomarkers. J Natl Cancer Inst 101(21): $1446-1452$.

Su L, Sampaio A, Jones K, Pacheco M, Goytain A, Lin S, Poulin N, Yi L, Rossi F, Kast J, Capecchi M, Underhill T, Nielsen T (2012) Deconstruction of the SS18-SSX fusion oncoprotein complex: insights into disease etiology and therapeutics. Cancer Cell 21(3): 333-347.

Susini T, Berti B, Carriero C, Tavella K, Nori J, Vanzi E, Molino C, Di Tommaso M, Santini M, Saladino V, Banchi S (2014) Topoisomerase II alpha and TLE3 as predcitive markers of response to anthracycline and taxane containing regimens for neoadjuvant chemotherapy in breast cancer. Onco Targets Ther 7: 2111-2120.

This work is published under the standard license to publish agreement. After 12 months the work will become freely available and the license terms will switch to a Creative Commons AttributionNonCommercial-Share Alike 4.0 Unported License.

Supplementary Information accompanies this paper on British Journal of Cancer website (http://www.nature.com/bjc) 